\title{
The Hydrobia ulvae-Maritrema subdolum association: influence of temperature, salinity, light, water-pressure and secondary host exudates on cercarial emergence and longevity
}

\author{
K.N. Mouritsen* \\ Department of Marine Ecology, Institute of Biological Sciences, University \\ of Aarhus, Finlandsgade 14, 8200 Aarhus N, Denmark
}

\begin{abstract}
The effects of environmental factors and exudates from the amphipod Corophium volutator on the emergence of Maritrema subdolum cercariae (Digenea: Microphallidae) from the snail Hydrobia ulvae were investigated in the laboratory. Increasing the temperature $\left(15\right.$ to $\left.25^{\circ} \mathrm{C}\right)$ caused an overall 11 -fold increase in emergence rate under varying salinities $(24$ to $36 \%$ ). The effect of salinity depended on the experimental temperature. Emergence increased with increasing salinity at higher temperatures, but decreased with increasing salinity at $15^{\circ} \mathrm{C}$. Whereas the different levels of salinity had no effect, increasing the temperature significantly reduced the life span of cercariae. In comparison with complete darkness, light caused a two-fold increase in emergence, whereas an increment of the water pressure from 1.0 to 1.3 ATM (corresponding to 0 and $3 \mathrm{~m}$ of depth) left the shedding rate unaffected. Unidentified exudates from the second intermediate host, $C$. volutator, significantly depressed the cercarial emergence rate. The main transmission window of M. subdolum seems to occur during low water in tidal pools where light levels are high and solar radiation rapidly elevates the water temperature, as well as salinity through evaporation. The consequence of such a transmission strategy is discussed in relation to the impact of M. subdolum on the population dynamics of the second intermediate host.
\end{abstract}

\section{Introduction}

Although digeneans often exhibit an impressive rate of asexual reproduction in the first intermediate host, the host is a limited resource and it may be selectively advantageous to the parasite to release cercariae under conditions where the likelihood of successful transmission is optimal (Combes et al., 1994). However,

*Address for correspondence: Department of Zoology, University of Otago, PO Box 56, Dunedin, New Zealand Fax: + 6434797584

E-mail: kim.mouritsen@stonebow.otago.ac.nz parasite invasion usually causes intensity-dependent pathology, and under optimal conditions for transmission this may lead to parasite-induced mortality affecting the population dynamics of the host (Anderson \& Gordon, 1982; Mouritsen \& Jensen, 1997; Bush et al., 2001). Identification of factors controlling cercarial emergence is therefore important in order to understand not only the maintenance of complex life cycles but also the potential of a given species of trematode to regulate the host population.

Maritrema subdolum (Microphallidae) is a marine digenean species that probably has its main distribution on intertidal flats where hydrobiid mud snails are used as 
the first intermediate host, various crustaceans (e.g. the infaunal amphipod Corophium volutator) as second intermediate host, and shorebirds as the final host (Mouritsen et al., 1997). Maritrema subdolum has, together with other microphallids, frequently been shown to inflict significant mortality upon its intermediate hosts (Lauckner, 1987a,b; Jensen \& Mouritsen, 1992; Meissner \& Bick, 1997, 1999a; Mouritsen \& Jensen, 1997), and hence retains the potential of regulating the intermediate host populations.

In tidal areas, regular exposure and flooding of the sea bottom causes the conditions for cercarial transmission (and its success) to be extremely variable both on a daily and, at higher latitudes, a seasonal basis. The pattern of cercarial release may be adapted accordingly. It is therefore of interest to identify the transmission window of $M$. subdolum and thus the conditions under which this parasite can be expected to compromise the survival of its intermediate hosts. Moreover, chemical communication through exudates appears to be a significant factor in the aquatic environment, relevant also to the transmission ecology of digeneans (Côté, 1995; Haas et al., 1995). Hence, the aims of the present study were to elucidate the influence of (i) prevailing abiotic variables in tidal habitats (temperature, salinity, light and water pressure) and (ii) host exudates as a poorly studied but potentially important biotic factor, on the emergence of $M$. subdolum cercariae from the snail Hydrobia ulvae.

\section{Materials and methods}

\section{Collection of snails and experimental protocol}

Specimens of $H$. ulvae were collected on an intertidal mudflat in the southern part of the Danish Wadden Sea $\left(54^{\circ} 56^{\prime} \mathrm{N}, 8^{\circ} 39^{\prime} \mathrm{E}\right)$. Trematode-infected snails were identified by the shedding of cercariae, which were identified according to Deblock (1980). Snails infected only by $M$. subdolum were stored in an aquarium, and two weeks prior to the experiments, snails were exposed to a constant temperature $\left(17^{\circ} \mathrm{C}\right)$ and salinity $(28 \%$ ), and a $12 / 12$ h day (700 lux)/night cycle.

Maritrema-infected snails were taken randomly from the storage aquarium and placed individually in $10 \mathrm{ml}$ transparent polystyrene dishes (except for the combined light-pressure experiment; see below) supplied with filtered, oxygen-saturated seawater with the desired experimental temperature. At the end of the experiments, snails were returned to the storage aquarium following measurements of their shell height, and released cercariae were counted. The average snail size did not differ significantly between treatments in any of the executed experiments.

\section{Temperature and salinity}

To elucidate the combined effect of temperature and salinity on cercarial emergence, 45 Maritrema-infected snails were placed in experimental dishes in each of three rooms kept at constant temperature of 15,20 and $25^{\circ} \mathrm{C}$. At each temperature, 15 dishes were supplied with $24 \%$ seawater, 15 with $30 \%$ water, and 15 with $36 \%$ water
( $\mathrm{n}=15$ for each of the resulting nine treatments). The experimental set-up was left under light (700 lux) for $12 \mathrm{~h}$.

The survival-rate of released Maritrema cercariae was investigated under the same temperature, salinity and light regime as above. Six to nine infected snails were placed together in each of five dishes and under each of nine temperature-salinity combinations $(n=5$ for each treatment). After $1 \mathrm{~h}$ (during which time on average 73 (range: 19-285) cercariae had emerged in each dish), the snails were removed and the bottom of the dish was inspected at regular time intervals for the presence of irreversibly grounded cercariae. These were defined as obviously weakened individuals showing either: (i) no movement at all; (ii) significantly reduced tail movements; or (iii) decaudation, excluding the possibility of self-induced resuspension. After 13-15 $\mathrm{h}$, the total number of cercariae present in each dish was determined. For each replicate, the proportion of cercariae still swimming as a function of time was calculated and an approximately functional survival curve produced.

\section{Light and water pressure}

The combined effect of light and pressure on cercarial emergence was investigated using a different experimental design. Ten $25 \mathrm{ml}$ transparent plastic flasks with screw caps were mounted on a horizontally placed armaturetube which was closed at one end and connected to another $285 \mathrm{~cm}$ long, open 'pressure-tube' at the other end. The flasks themselves could be removed, whereas their caps were fixed onto the armature-tube by penetrating pipes. Four such experimental units were filled with seawater $\left(22^{\circ} \mathrm{C}, 28 \%\right.$ o $)$, and one infected snail was placed in each flask. The armature-tube and attached flasks of two of four experimental units were enclosed in a light proof box. The pressure-tube of one enclosed and one unenclosed unit was raised to a vertical position thereby producing a pressure of about 1.3 ATM in the snail-containing flasks (corresponding to $3 \mathrm{~m}$ of depth). The pressure-tubes of the two remaining units were kept almost horizontal causing a pressure of about 1.0 ATM in the flasks. This experimental set-up was left for $12 \mathrm{~h}$ under illumination (5500lux). A pilot experiment in which the transparent armature-tube was inspected through a stereomicroscope ensured that cercariae did not escape from the flasks through the connecting pipes.

\section{Host exudates}

In order to clarify whether exudates from the intermediate hosts $H$. ulvae and $C$. volutator affect cercarial emergence, three experiments were carried out.

Experiment I: two buckets each containing 31 of filtered $28 \%$ sea water (taken from a shallow-watered stony reef supporting an animal community without Hydrobia and Corophium ) were established at $21^{\circ} \mathrm{C}$ with an efficient airsupply. About 3600 specimens of $C$. volutator were added to one of the buckets. Following a period of $32 \mathrm{~h}$, water from the buckets was filtered through a $125 \mu \mathrm{m}$ mesh. The $\mathrm{pH}$ of both control and Corophium-conditioned water was about 8.0. Thirty-one infected snails were then placed individually in dishes of which 13 were supplied with Corophium-conditioned water and 18 with control water. 
The dishes were left for $6 \mathrm{~h}$ under illumination (88lux) and at a constant temperature of $21^{\circ} \mathrm{C}$.

Experiment II: similar to experiment I, except that approximately 5000 specimens of $H$. ulvae instead of Corophium were added to one of the buckets for $25 \mathrm{~h}$, and that $\mathrm{n}=16$ for each treatment.

Experiment III: similar to experiment II, except that approx. 1500 specimens of $C$. volutator instead of Hydrobia were added to one of the buckets for $7 \mathrm{~h}$.

\section{Data analysis}

Statistical analyses were performed using SPSS. Parametric tests were preceded by tests of their assumptions (normal distribution and homogeneity of variance). Where these assumptions were violated, nonparametric statistics were applied or data were transformed in order to meet the assumptions. Standard transformations failed to stabilize the error variance in emergence data from the temperature-salinity experiment, and an exclusion of snails that did not release cercariae followed by a ln-transformation was necessary in order to perform a two-way ANOVA. Exclusion of data caused the sample size in each treatment to vary between 12 and 15. This slight imbalance was not considered important in the light of the highly significant effects obtained.

Regarding survival data, the area below the survival curves rather than the $\mathrm{GT}_{50}$-value (elapsed time until $50 \%$ of the cercariae were irreversibly grounded) was used as the main unit for analysis, as this area can be used to transform cercarial production into an estimate of the transmission pressure ('cercariae-minutes') experienced by the second intermediate host. Comparing the temperature-salinity dependent emergence pattern with a similar pattern of 'cercariae-minutes' will elucidate the relative importance of cercarial production and survival in determining the transmission pressure and window.

\section{Results}

\section{Effect of temperature and salinity on cercarial emergence}

A full model two-way ANOVA revealed a highly significant interaction between the effect of temperature and salinity on emergence rate $\left(\mathrm{F}_{4,116}=8.98, P<0.001\right)$ (fig. 1). Hence, the effect of each of the two factors, holding the other one constant, was analysed using all data available. At each salinity $(24,30$ and $36 \%$ ) there was a strong positive effect of increasing temperature on the rate of emergence (Kruskal-Wallis test, $\chi_{2}^{2}>14.3$, $P<0.001)$. The effect of salinity, however, varied with the experimental temperature (fig. 1). Although emergence was generally low at $15^{\circ} \mathrm{C}$, the shedding rate decreased eight-fold as the salinity increased from 24 to $36 \%$ (Kruskal-Wallis test, $\chi_{2}^{2}>11.2, \quad P<0.004$ ). In contrast, at $20^{\circ} \mathrm{C}$, the shedding rate increased about twofold with increasing salinity (Kruskal-Wallis test, $\chi_{2}^{2}>$ 8.2, $P<0.017)$. At $25^{\circ} \mathrm{C}$ no significant effect of salinity could be demonstrated on the number of released cercariae (Kruskal-Wallis test, $\chi_{2}^{2}<0.80, P>0.67$ ).

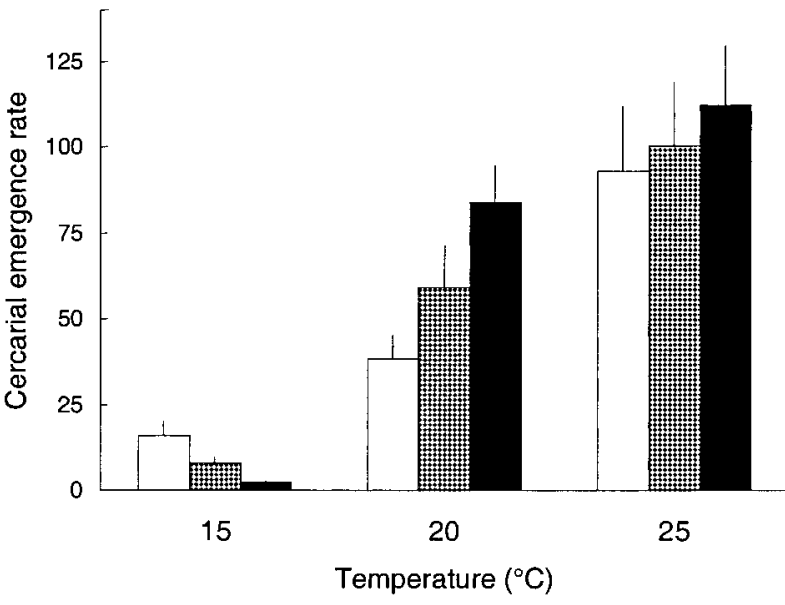

Fig. 1. The effect of temperature and salinity $(\square, 24 \%$; $19 \%$ $36 \%$ ) on the emergence rate of Maritrema subdolum cercariae from Hydrobia ulvae (mean number per snail per $12 \mathrm{~h} \pm \mathrm{SE}$ ) at different temperature-salinity combinations.

\section{Effect of temperature and salinity on cercarial longevity and} transmission pressure

A full model two-way ANOVA applied to survival data revealed no significant interaction between the effect of temperature and salinity $\left(\mathrm{F}_{4,36}=0.07, P=0.99\right)$. The subsequent reduced model revealed a significant effect of temperature $\left(\mathrm{F}_{2,40}>38.7, P<0.001\right)$ but salinity had no effect $\left(\mathrm{F}_{2,40}=0.77, P=0.47\right)$. Hence, salinity treatments at the same temperature were pooled, and data were reanalysed for the effect of temperature using a one-way ANOVA followed by a Bonferroni post hoc test. The significant effect of temperature was confirmed $\left(\mathrm{F}_{2,42}=39.2, P<0.0001\right)$, and it was demonstrated that the three experimental temperatures all had significantly different effects on the survival of released cercariae $(P<0.05$ for all possible pair-wise comparisons) where cercarial survival increased with decreasing temperature (fig. 2). Cercariae showed the first sign of decay about $6 \mathrm{~h}$ after release and became more or less immobilized after 13-17 $\mathrm{h}$. Depending on experimental temperature, the $\mathrm{GT}_{50}$-values varied between 8.5 and $13.5 \mathrm{~h}$.

As an estimate of the time-dependent functional survival of released cercariae, the area below the survival curves was on average 749,591 and $535 \mathrm{~min}$ at respectively 15,20 and $25^{\circ} \mathrm{C}(\mathrm{n}=15$ at each temperature since salinity treatments were pooled). Emergence data were modified according to these mean values thereby obtaining temperature-salinity dependent 'cercariaeminutes' as a measure of the transmission pressure. The derived data were analysed as described above. The result was qualitatively similar to that based on emergence data by demonstrating a significant increase in the transmission pressure with increasing temperature at all three experimental salinities (Kruskal-Wallis test, $\left.\chi_{2}^{2}>11.3, P<0.004\right)$. However, the pattern of temperature-salinity dependent transmission pressure (not shown) revealed negligible deviation from the emergence data (fig. 1) regarding the relative impact of the three experimental temperatures. This is partly due to the 


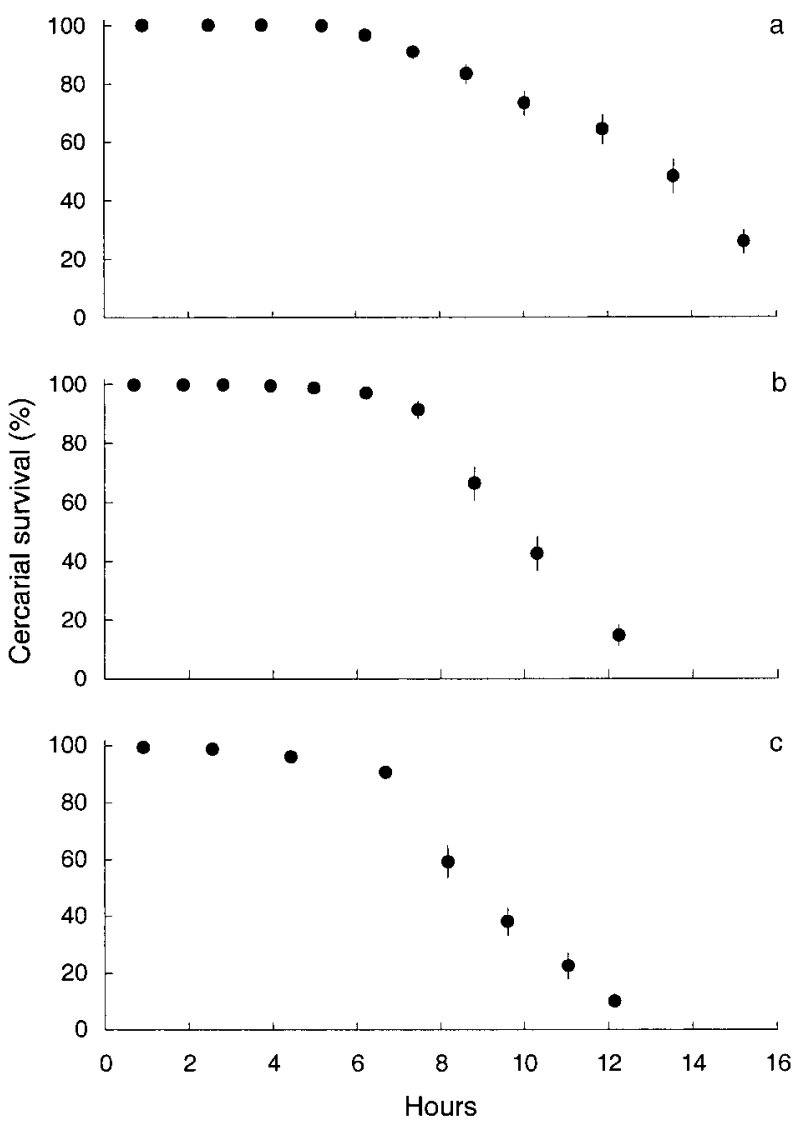

Fig. 2. The effect of temperature on survival (mean $\% \pm S E$ ) of Maritrema subdolum cercariae as a function of time at (a) $15^{\circ} \mathrm{C}$, (b) $20^{\circ} \mathrm{C}$ and (c) $25^{\circ} \mathrm{C}$.

minor difference in cercarial longevity between 20 and $25^{\circ} \mathrm{C}$, and partly because the number of released cercariae at $15^{\circ} \mathrm{C}$ was insufficient to affect the overall picture even following a correction for the considerably longer life span at that temperature. It suggests that the influence of temperature on emergence overrides the influence of temperature on cercarial survival as a determinant of transmission pressure and window.

\section{Effect of light and water pressure on cercarial emergence}

A full model two-way ANOVA performed on the combined light-pressure data showed a non-significant interaction between the two factors $\left(\mathrm{F}_{1,36}=0.02, P>\right.$ $0.89)$. The subsequent reduced model, showed a significant effect of light $\left(\mathrm{F}_{1,37}=5.61, P=0.023\right)$, but no significant influence of pressure $\left(\mathrm{F}_{1,37}=0.38, P=0.54\right)$. Hence, in comparison with complete darkness the presence of light caused about a two-fold higher cercarial production whereas the $30 \%$ pressure-increase had no significant impact (fig. 3). With reference to light, a similar result was also obtained in a separate experiment that followed the general experimental protocol (see Mouritsen, 2002).

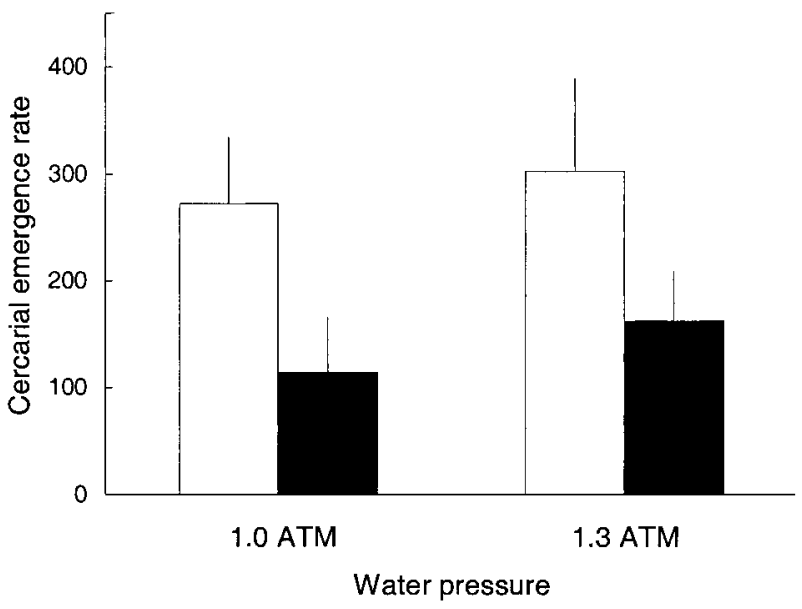

Fig. 3. The effect of light intensity ( $\square, 0$ lux; $\square, 5500$ lux $)$ on the emergence rate of Maritrema subdolum cercariae from Hydrobia ulvae (mean number per snail per $12 \mathrm{~h} \pm \mathrm{SE}$ ) at different combinations of light intensity and water pressure.

\section{Effect of host exudates on cercarial emergence}

Exudates from C. volutator depressed cercarial emergence significantly. More than twice as many cercariae were released from snails in control water than from snails exposed to both low and high concentrations of Corophium-exudates (table 1). However, only the difference at the higher exudate-concentration was statistically significant. In contrast, no significant difference between cercarial emergence from snails in control water and snails in Hydrobia-treated water could be demonstrated (table 1).

\section{Discussion}

Regardless of salinity, an increase in temperature had a strong positive effect on the emergence of Maritrema cercariae within the investigated temperature range, considerably beyond a generalized $\mathrm{Q}_{10}$-effect (a two-fold increase with a temperature increase of $10^{\circ} \mathrm{C}$ ). This suggests, in accordance with Ginetsinskaya (1988), that temperature directly or indirectly triggers the release of cercariae rather than just accelerating the cercarial maturation process. Studies on other host-parasite associations have generally reached similar conclusions: until a certain upper temperature limit, determined largely by the temperature tolerance of the host itself (Erasmus, 1972; Ataev, 1991), there exists a positive relationship between cercarial emergence and temperature (Kuntz, 1947; Rojo-Vázquez \& Simón-Martín, 1985; Shostak \& Esch, 1990; Lo \& Lee, 1996; Umadevi \& Madhavi, 1997).

Since the emergence pattern of marine trematodes has rarely been studied, the role of salinity is poorly elucidated. However, available information shows that cercarial emergence generally increases with increasing salinity within a range of values usually occurring in coastal habitats (Rees, 1948; Sindermann, 1960; Sindermann \& Farrin, 1962). Here, in terms of transmission pressure, salinity was quantitatively the most important 
Table 1 . The mean number $( \pm \mathrm{SD})$ of Maritrema subdolum cercariae released per snail during $6 \mathrm{~h}$ in water containing secondary host exudates (treated) and filtered, untreated seawater (control).

\begin{tabular}{lccccc}
\hline & \multicolumn{2}{c}{ Mean cercarial emergence \pm SD (n) } & & \\
\cline { 2 - 3 } Treatment & Treated snails & Control snails & & $\mathrm{Z}$ & \multicolumn{1}{c}{$P$} \\
\hline Corophium exudates & & & & \\
$\quad$ Low concentration & $48.9 \pm 55.1(16)$ & $110.3 \pm 126.8(16)$ & 1.28 & 0.20 \\
$\quad$ High concentration & $88.1 \pm 42.0(13)$ & $204.1 \pm 141.9(18)$ & 2.64 & 0.008 \\
Hydrobia exudates & $147.3 \pm 215.4(16)$ & $187.4 \pm 280.5(16)$ & 0.08 & 0.94 \\
\hline
\end{tabular}

$\mathrm{Z}$ and $P$ denote test statistic and significance level based on Mann-Whitney tests, respectively. Corophium exudates, low concentration: 500 amphipods per litre water for $7 \mathrm{~h}$. Corophium exudates, high concentration: 1200 amphipods per litre for $32 \mathrm{~h}$. Hydrobia exudates: 1667 snails per litre water for $25 \mathrm{~h}$.

at an intermediate temperature $\left(20^{\circ} \mathrm{C}\right)$ causing about a two-fold increase in the cercarial emergence rate with an increase of about $10 \%$. Similar quantitative effects were found in the papers cited.

The salinity range used in the present study had no effect on the longevity of Maritrema cercariae, in accordance with a large salinity tolerance previously observed in M. subdolum and other marine cercariae (Stunkard \& Shaw, 1931; Rees, 1948; James, 1971; Prokofiev, 1999). In contrast, increasing the temperature significantly reduced the life span of cercariae, which is also in agreement with previous studies on M. subdolum and a range of other digeneans (Lawson \& Wilson, 1980; Evans, 1985; Shostak, 1993; Lowenberger \& Rau, 1994; Pechenik \& Fried, 1995; Lo \& Lee, 1996; Meissner \& Bick, 1999b; Prokofiev, 1999).

$\mathrm{LT}_{50}$-values of cercariae have been reported to vary widely depending on the species studied (usually 1-4 days at $20^{\circ} \mathrm{C}$; Lawson \& Wilson, 1980; Rojo-Vázques \& Simón-Martín, 1985; Rea \& Irwin, 1992; Shostak, 1993; McCarthy, 1999; Meissner \& Bick, 1999b). Such speciesspecific variation may reflect that the amount of energy a given trematode species allocates to cercarial longevity is optimized according to the likelihood of meeting a suitable host as a function of time. Meissner \& Bick (1999b) found $\mathrm{LT}_{50}$-values between 21 and $32 \mathrm{~h}$ for $M$. subdolum within a temperature range similar to the one used here. Since the infective life span of cercariae typically is $20-50 \%$ of their formal longevity estimates (Lowenberger \& Rau, 1994; Pechenik \& Fried, 1995), functional $\mathrm{LT}_{50}$-values of Maritrema cercariae may lie between 5 and $16 \mathrm{~h}$. These figures correspond well with $\mathrm{GT}_{50}$-values obtained in the present study $(8-14 \mathrm{~h})$, suggesting that the survival curves (fig. 2) actually approximate functional longevity. Moreover, because the main transmission window of M. subdolum is probably the low tide period in intertidal areas (see below), having a duration of about $6-12 \mathrm{~h}$ on the upper part of the tidal flat, the observed functional life span may be close to energetically optimal. Cercariae surviving beyond the point of tidal inundation may experience difficulties in reaching the bottom-dwelling second intermediate host (e.g. corophiids) due to dislodgment by tidal currents and dilution in the rapidly increasing body of incoming water.

Albeit clearly secondary to the impact of temperature, light enhances the emission of Maritrema cercariae. Qualitative and quantitative impacts of light on cercarial emergence strongly depend on the specific host-parasite system. Among existing marine studies, Rees (1948) showed that shedding increased under light in the Nucella lapillus-Cercariae purpurae association, whereas Craig (1975) found emergence to be stimulated by darkness and light in the Ilyanassa obsoleta-Himasthla quissetensis and the I. obsoleta-Lepocreadium setiferoides associations, respectively. Ginetsinskaya (1988), on the other hand, mentions that the emergence of $M$. subdolum from an unspecified host was unaffected by light levels, but provided no experimental evidence or details that might help unravel the discrepancy between this work and the present findings.

Exudates from $C$. volutator caused an immediate depression of cercarial emission. Since Hydrobia-exudates did not elicit similar responses, this observation seems non-trivial and suggests that the presently unknown active compound in the exudates can be specific for crustaceans if not Corophium. Because C. volutator and $H$. ulvae usually coexist on intertidal flats (Mouritsen et al., 1997) and because microphallid trematodes of $H$. ulvae retain the potential of killing their amphipod second intermediate host, the production and release of exudates by $C$. volutator that depress cercarial emergence might be an anti-parasitic adaptation. No comparable observation exists in other systems. It has been shown that the presence of host or non-host snails may (depending on density) increase or decrease cercarial output from infected snail species (Moné, 1991; Ferrer et al., 1991; Mouahid et al., 1992). This is not an immediate response though, and can largely be ascribed to the long-term positive or negative effect that non-target snails have on the growth rate of target snails and hence size-dependent cercarial production (but see Coles, 1973).

From the present experiments it cannot be deduced whether the emergence-controlling factors act in an additive or compensatory manner. However, fig. 1 shows that salinity is less influential at higher temperatures suggesting that the isolated effect of temperature and salinity respectively may be additive only at lower levels. This may apply to all influential factors. Nevertheless, as light, increasing temperature and increasing salinity (at the higher temperatures) positively affected cercarial 
emergence, the main transmission window of Maritrema cercariae in temperate intertidal areas should occur from spring to autumn in intertidal pools during sunny low tides where radiation and evaporation rapidly elevates both temperature and salinity. This scenario agrees well with survival data suggesting a functional longevity corresponding to the duration of the low tide period. The trematodes achieve three obvious benefits from this emergence pattern. Firstly, the cercariae are released into a small volume of water thereby optimizing the concentration of cercariae and hence transmission rate (see Mouritsen \& Jensen, 1997). Secondly, as water movements are insignificant in tidal pools, cercariae avoid dislodgment and interference with their necessary swimming activity in order to achieve contact with the next host. Thirdly, cercariae will emerge under conditions that also stimulate Corophium activity (Meadows \& Ruagh, 1981a,b) and since the likely route of transmission is via the amphipod's ventilation current, a higher Corophium activity will increase the transmission success.

Temperate regions are often characterized by repeated passages of cyclones over short time-scales giving rise to periods of cloudy, rainy and relatively cold weather alternating with sunny and relatively warm conditions. Superimposed upon these changing weather conditions is the regular exposure of the seabed in tidal areas. This means that temperate intertidal flats are exposed to shortterm fluctuations in cercarial emergence-controlling abiotic conditions with amplitudes exceeding those of most other marine habitats. Moreover, microphallid trematodes develop sporocysts from which cercariae are released simultaneously at the point of maturation if conditions otherwise are right. Under conditions unfavourable for cercarial release (e.g. during a cyclone passage), the maturation process may nonetheless continue causing the entire infrapopulation of Maritrema cercariae to be prepared for release when conditions improve. Such a scenario predicts that trematode larvae tend to emerge in synchronized cycles producing waves of transmission. Since the detrimental pathology inflicted by microphallids on the second intermediate hosts is intensity-dependent (Mouritsen \& Jensen, 1997; Meissner \& Bick, 1999a), there will be an inherently high probability that these pulses of transmission may develop into epizootic-like patterns of mortality in the population of second intermediate hosts if the abundance of infected snails is high. Evidence supporting this prediction is presented elsewhere (Jensen \& Mouritsen, 1992; Mouritsen et al., 1997). In non-tidal areas where short-term fluctuations in the emergence-controlling conditions are less pronounced, epizootics may be less likely to develop, although microphallid-induced regulation of the second intermediate host population may occur (Meissner \& Bick, 1997).

\section{Acknowledgements}

The work was supported by a grant from The Carlsberg Foundation. During preparation of the manuscript, support was provided by The Danish Natural Science Research Council and The Marsden Foundation (New Zealand). I also wish to thank K. Thomas Jensen, Robert
Poulin and referees for useful comments on an earlier draft.

\section{References}

Anderson, R.M. \& Gordon, D.M. (1982) Processes influencing the distribution of parasite numbers within host populations with special emphasis on parasite-induced host mortality. Parasitology 85, 373-398.

Ataev, G.L. (1991) Temperature influence on the development and biology of redia and cercariae of Philophthalmus rhionica (Trematoda). Parazitologiya 25, 349-359 (in Russian).

Bush, O.B., Fernández, J.C., Esch, G.W. \& Seed, J.R. (2001) Parasitism. The diversity and ecology of animal parasites. Cambridge, Cambridge University Press.

Coles, G.C. (1973) The effect of diet and crowding on the shedding of Schistosoma mansoni cercariae by Biomphalaria glabrata. Annals of Tropical Medicine and Parasitology 67, 419-423.

Combes, C., Fournier, A., Moné, H. \& Théron, A. (1994) Behaviours in trematode cercariae that enhance parasite transmission: patterns and processes. Parasitology 109, S3-S13.

Côté, I.M. (1995) Effects of predatory crab effluent on byssus production in mussels. Journal of Experimental Marine Biology and Ecology 188, 233-241.

Craig, L.H. (1975) Himasthla quissentensis and Lepocreadium setiferoides: emergence patterns from their molluscan host, Nassarius obsoletus. Experimental Parasitology 38, 56-63.

Deblock, S. (1980) Inventaire des trématodes larvaires parasites des mollusques Hydrobia (Prosobranches) des côtes de France. Parassitologia 22, 1-105.

Erasmus, D.A. (1972) The biology of trematodes. Belfast, The University Press.

Evans, N.A. (1985) The influence of environmental temperature upon transmission of the cercariae of Echinostoma liei (Digenea: Echinostomatidae). Parasitology 90, 269-275.

Ferrer, J.R., Pointier, J.-P., Théron, A. \& Moné, H. (1991) Influence of the nontarget mollusc Marisa cornuarietis on the hourly cercarial production of Schistosoma mansoni from Biomphalaria glabrata. Journal of Parasitology 77, 798-800.

Ginetsinskaya, T.A. (1988) Trematodes, their life cycles, biology and evolution. New Delhi, Amerind Publishing Co. Pvt. Ltd.

Haas, W., Haberl, B., Kalbe, M. \& Körner, M. (1995) Snail-host-finding by miracidia and cercariae: chemical host cues. Parasitology Today 11, 468-472.

James, B.L. (1971) Host selection and ecology of marine digenean larvae. pp. 179-196 in Crisp, D.J. (Ed.) Fourth European marine biology symposium. Cambridge, Cambridge University Press.

Jensen, K.T. \& Mouritsen, K.N. (1992) Mass mortality in two common soft-bottom invertebrates, Hydrobia ulvae and Corophium volutator - the possible role of trematodes. Helgoländer Meeresuntersuchungen 46, 329-339.

Kuntz, R.E. (1947) Effect of light and temperature on 
emergence of Schistosoma mansoni cercariae. Transactions of the American Microscopical Society 66, 37-49.

Lauckner, G. (1987a) Effects of parasites on juvenile Wadden Sea invertebrates. pp. 103-121 in Tougaard, S. \& Asbirk, S. (Eds) Proceedings of the 5th international Wadden Sea symposium. Esbjerg, The National Forest and Nature Agency and Museum of Fisheries and Shipping.

Lauckner, G. (1987b) Ecological effects of larval trematode infections on littoral marine invertebrate populations. International Journal for Parasitology 17, 391-398.

Lawson, J.R. \& Wilson, R.A. (1980) The survival of the cercariae of Schistosoma mansoni in relation to water temperature and glycogen utilization. Parasitology 81, 337-348.

Lo, C.-T. \& Lee, K.-M. (1996) Pattern of emergence and the effects of temperature and light on the emergence and survival of heterophyid cercariae (Centrocestus formosanus and Haplorchis pumilio). Journal of Parasitology 82, 347-350.

Lowenberger, C.A. \& Rau, M.E. (1994) Plagiorchis elegans: emergence, longevity and infectivity of cercariae, and host behavioural modifications during cercarial emergence. Parasitology 109, 65-72.

McCarthy, A.M. (1999) The influence of temperature on the survival and infectivity of the cercariae Echinoparyphium recurvatum (Digenea: Echinostomatidae). Parasitology 118, 383-388.

Meadows, P.S. \& Ruagh, A.A. (1981a) Multifactorial analysis of behavioural responses of the amphipod Corophium volutator to temperature-salinity combinations. Marine Ecology Progress Series 6, 183-190.

Meadows, P.S. \& Ruagh, A.A. (1981b) Temperature preference and activity of Corophium volutator (Pallas) in a new choice apparatus. Sarsia 66, 67-72.

Meissner, K. \& Bick, A. (1997) Population dynamics and ecoparasitological surveys of Corophium volutator in coastal waters in the Bay of Mecklenburg (southern Baltic Sea). Diseases of Aquatic Organisms 29, 169-179.

Meissner, K. \& Bick, A. (1999a) Mortality of Corophium volutator (Amphipoda) caused by infestation with Maritrema subdolum (Digenea, Microphallidae) laboratory studies. Diseases of Aquatic Organisms 35, 47-52.

Meissner, K. \& Bick, A. (1999b) Laboratory studies of parasite transmission aspects between Hydrobia spp. (Gastropoda) and Corophium volutator (Amphipoda). International Review of Hydrobiology 84, 61-72.

Moné, H. (1991) Influence of non-target molluscs on the growth of Biomphalaria glabrata infected with Schistosoma mansoni: correlations between growth and cercarial production. Journal of Molluscan Studies 57, $1-10$.

Mouahid, A., Bouhaddioui, N., Jana, M., Combes, C. \& Moné, H. (1992) Effect of different mollusc associations on target mollusc growth and parasite cercarial production in the triple system: Bulinus wrightiSchistosoma bovis and Melanopsis praemorsa. Journal of Molluscan Studies 58, 349-355.

Mouritsen, K.N. (2002) The Hydrobia ulvae-Maritrema subdolum association: cercarial emergence controlled by host activity. Journal of Helminthology 76, 349-353.
Mouritsen, K.N. \& Jensen, K.T. (1997) Parasite transmission between soft-bottom invertebrates: temperature mediated infection rates and mortality in Corophium volutator. Marine Ecology Progress Series 151, 123-134.

Mouritsen, K.N., Jensen, T. \& Jensen, K.T. (1997) Parasites on an intertidal Corophium-bed: factors determining the phenology of microphallid trematodes in the intermediate host populations of the mud-snail Hydrobia ulvae and the amphipod Corophium volutator. Hydrobiologia 355, 61-70.

Pechenik, J.A. \& Fried, B. (1995) Effect of temperature on survival and infectivity of Echinostoma trivolis cercariae: a test of the energy limitation hypothesis. Parasitology 111, 373-378.

Prokofiev, V.V. (1999) Influence of temperature and salinity on a life span of cercariae of littoral trematodes Cryptocotyle sp. (Heterophyidae), Levinseniella brachysoma and Maritrema subdolum (Microphallidae). Parazitologiya 33, 520-525 (in Russian).

Rea, J.G. \& Irwin, S.W.B. (1992) The effects of age, temperature, light quantity and wavelength on the swimming behaviour of the cercariae of Cryptocotyle lingua (Digenea: Heterophyidae). Parasitology 105, $131-137$.

Rees, G. (1948) A study of the effect of light, temperature and salinity on the emergence of Cercaria purpurae Lebour from Nucella lapillus (L.). Parasitology 38, $228-242$.

Rojo-Vázquez, F.A. \& Simón-Martín, F. (1985) Algunos aspectos de la biologia de las cercarias de Trichobilharzia sp. del Rio Cañedo (provincia de Salamanca, España). Revista Ibérica de Parasitologia 45, 141-148.

Shostak, A.W. (1993) Survival of Petasiger nitidus (Digenea: Echinostomatidae) cercariae in relation to temperature, $\mathrm{pH}$, and salinity. Canadian Journal of Zoology 71, 431-434.

Shostak, A.W. \& Esch, G.W. (1990) Photocycle-dependent emergence by cercariae of Halipegus occidualis from Helisoma anceps, with special reference to cercarial emergence patterns as adaptations for transmission. Journal of Parasitology 76, 190-195.

Sindermann, C.J. (1960) Ecological studies of marine dermatitis-producing schistosome larvae in northern New England. Ecology 41, 678-684.

Sindermann, C.J. \& Farrin, A.E. (1962) Ecological studies of Cryptocotyle lingua (Trematoda: Heterophyidae) whose larvae cause 'pigment spots' of marine fish. Ecology 43, 69-75.

Stunkard, H.W. \& Shaw, C.R. (1931) The effect of dilution of sea water on the activity and longevity of certain marine cercariae, with descriptions of two new species. Biological Bulletin, Woods Hole 61, 242-271.

Umadevi, K. \& Madhavi, R. (1997) Effects of light and temperature on the emergence of Haplorchis pumilio cercariae from the snail host Thiara tuberculata. Acta Parasitologica 42, 12-16. 